\title{
Optimal Choice of Coronary Revascularization and Stent Type in Diabetic Patients with Coronary Artery Disease
}

Ralf E. Harskamp • Duk-Woo Park

To view enhanced content go to www.cardiologytherapy-open.com

Received: February 1, 2013 / Published online: March 26, 2013

(C) The Author(s) 2013. This article is published with open access at Springerlink.com

\section{ABSTRACT}

Patients with diabetes mellitus (DM) are prone to a diffuse and accelerated form of coronary artery disease (CAD), which in turn is a major cause of cardiac-related morbidity and mortality. Compared with patients without diabetes, patients with diabetes undergoing coronary revascularization are at higher risk of procedural, short-, and long-term cardiovascular events and mortality. Although coronary artery bypass grafting (CABG) has

R. E. Harskamp

Academic Medical Center, University of

Amsterdam, Amsterdam, The Netherlands

R. E. Harskamp · D.-W. Park

Duke Clinical Research Institute, Duke University

Medical Center, 2400 Pratt St., Durham, NC 27715, USA

D.-W. Park $(\bowtie)$

Department of Cardiology, University of Ulsan College of Medicine, Asan Medical Center, 388-1 Poongnap-dong, Songpa-gu, Seoul 138-736, Korea e-mail: dwpark@amc.seoul.kr

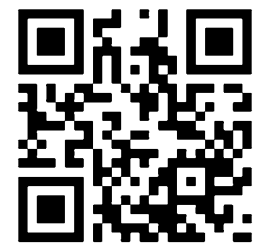

Enhanced content for this article is available on the journal web site: www.cardiologytherapy-open.com been regarded as the primary revascularization strategy in diabetic patients with complex CAD, percutaneous coronary intervention (PCI) is an effective revascularization alternative, due to remarkable advances in stent devices and adjunctive drug therapies. Outcomes data, from subgroup analyses and small-sized clinical trials and large registries, have suggested that PCI with current stent technology showed comparable long-term risks of mortality and hard endpoints, but higher risk of repeat revascularization for the diabetic population compared to CABG. However, the recent landmark International Future REvascularization Evaluation in patients with diabetes mellitus: optimal management of Multivessel disease (FREEDOM) trial provides compelling evidence of the superiority of CABG over PCI in reducing the rates of death, myocardial infarction, at the expense of stroke, in patients with diabetes with advanced CAD. When opting for PCI in patients with diabetes, currently used drugeluting stents (DES) are more efficient in reducing the risk of repeat revascularization without compromising safety outcomes, compared to bare-metal stents. The selection 
of a specific type of DES in patients with diabetes is controversial and therefore more data comparing second- and newer-generation DES for patients with diabetes are currently needed. Also, efforts to make more advanced DES platforms suitable for patients with diabetes with complicated angiographic features are still ongoing.

Keywords: Coronary artery bypass grafting; Coronary artery disease; Diabetes mellitus; Drug-eluting stents; Percutaneous coronary intervention

\section{INTRODUCTION}

Over the last decades, the prevalence of diabetes mellitus (DM) has significantly increased worldwide [1]. Coronary artery disease (CAD) is a major cause of morbidity and mortality among patients with DM. Compared to individuals without diabetes, those with diabetes have a higher prevalence of CAD, present at an earlier age, and have a greater extent of coronary atherosclerosis [2].

Due to the aggressive form of CAD, a large proportion of diabetic patients require intensive medical treatment and surgical or percutaneous coronary revascularization, and therefore optimal decision-making on medical and revascularization strategies of significant CAD is crucial to obtain better long-term outcomes in such patients.

For patients with diabetes requiring coronary revascularization, coronary artery bypass grafting (CABG) has been considered the preferred revascularization strategy because of concerns regarding higher risk of restenosis and ischemic cardiovascular complications, and uncertainty of very long-term durability of percutaneous coronary intervention (PCI) [3].
However, with rapid advancements of novel PCI devices, techniques, and adjunctive drug therapy, clinical results of PCI for patients with diabetes have been markedly improved, and also newer technologies are continuously developing to enhance clinical outcomes in diabetic patients with complex clinical and angiographic characteristics [4].

In this review of the literature, the key clinical studies comparing medical, percutaneous, or surgical management for diabetic patients with CAD have been summarized, and the authors also compare PCI outcomes among several stent types in patients with diabetes. This review provides valuable information for optimal selection of revascularization strategy as well as PCI devices for patients with diabetes with higher clinical and angiographic risk profiles.

\section{MATERIALS AND METHODS}

The authors searched PubMed, Embase, and the Cochrane Central Register of Controlled Trials (CENTRAL) for randomized clinical trials and prospective or retrospective observational studies using the terms: "diabetes mellitus," "revascularization," "coronary artery bypass grafting," "percutaneous coronary intervention," "antiplatelet therapy," and the names of individual stent systems (bare-metal stents, sirolimus-eluting stents, paclitaxel-eluting stents, everolimus-eluting stents, zotarolimuseluting stents, biodegradable polymer drugeluting stents, and bioabsorbable coronary stents) until November 2012. We also checked the reference lists of review articles, metaanalyses, and original studies identified by the electronic searches to find other eligible studies for systemic reviews. There was no language restriction for the search. In addition, we 
searched conference proceedings/abstracts from the American Heart Association, American College of Cardiology, Transcatheter Cardiovascular Therapeutics, Society of Cardiovascular Angiography and Intervention, European Society of Cardiology, and Euro-PCR. Two authors (R.E.H., D.W.P.) collaboratively assessed studies eligibility for this systemic review.

\section{DISCUSSION}

\section{Diabetic Impact on Outcomes after CABG and PCI}

Outcomes after surgical or percutaneous revascularization are uniformly worse in patients with diabetes as compared to those without diabetes. The presence of diabetes has negatively affected outcomes following CABG surgery and so the rates of death and adverse cardiovascular events after CABG were significantly higher in patients with diabetes compared to those without diabetes. An analysis from the Society of Thoracic Surgery database ( $n=146,786)$ showed early (30-day) mortality of $3.7 \%$ in patients with diabetes following CABG, compared with $2.7 \%$ in those without diabetes (adjusted odds ratio: 1.23, 1.15-1.32) [5]. In particular, patients with diabetes requiring insulin therapy were at higher risk (adjusted odds ratio: $1.39,1.27-1.52$ ) than those on oral hypoglycemic medications (adjusted odds ratio: 1.13, 1.04-1.23) as compared with patients without diabetes. Diabetes is also associated with more perioperative noncardiac morbidity, including ischemic or hemorrhagic stroke, renal failure, infections, and longer length of hospital stay. Infection, particularly mediastinitis due to impaired sternal wound healing, is of particular concern in patients with diabetes [6]. This risk may be reduced by maintenance of strict glycemic control during the perioperative period. The need for additional revascularization by graft failure is also more common in patients with diabetes following CABG [7].

Similarly to what is observed in patients undergoing CABG surgery, diabetes is also associated with poorer clinical outcomes after PCI. Although the procedural success rates are relatively similar in patients with and without diabetes, patients with diabetes have higher rates of restenosis and long-term cardiovascular events than patients without diabetes [8-10]. Similarly to a significantly higher rate of restenosis in patients with diabetes undergoing bare-metal stent (BMS) implantation than patients without diabetes (31\% vs. $21 \%, P<0.001)[8]$, a large registry using sirolimus-eluting stents (SES) showed an incremental increase of target-lesion revascularization (TLR) at 3 years according to the severity of diabetic status $(10 \%$ in patients without diabetes, $14 \%$ in patients with noninsulin-dependent diabetes, and 19\% in patients with insulin-dependent diabetes) [11]. Diabetes is also associated with higher rates of myocardial infarction (MI) and mortality following PCI. An observational study with BMS showed survival rates (91.7\% vs. $96.2 \%)$ and freedom from MI (89.9\% vs. $94.4 \%)$ was significantly lower in the diabetic population than in the nondiabetic population [12]. Similarly, observation registry with drug-eluting stent (DES) showed that 3-year mortality was significantly higher in patients with diabetes than in those without $(17.3 \%$ vs. $7.8 \%)$ [13]. Some studies suggest that the clinical impact of diabetes may vary among various ethnic populations [17-19].

\section{Optimal Treatment Selection: Medical} Versus Revascularization

Optimal treatment for patients with both type 2 $\mathrm{DM}$ and stable CAD has been controversial. The 
best available evidence regarding optimal therapy for patients with diabetes with stable angina is derived from the Bypass Angioplasty Revascularization Investigation 2 Diabetes (BARI 2D) Trial [14], in which 2,368 patients with diabetes with significant CAD were randomized to undergo either prompt revascularization with intensive medical therapy or intensive medical therapy alone, and to undergo either insulinsensitization or insulin-provision therapy. Primary results showed no difference in longterm mortality and major adverse cardiac events (MACE; a composite of death, MI, or stroke) between patients with intensive medical treatment and those with prompt (surgical or percutaneous) revascularization. In the PCI stratum, there was no significant difference in primary endpoints between the revascularization group and the medical therapy group. However, in the CABG stratum, the rate of MACE was significantly lower in the revascularization group than in the medical therapy group $(22.4 \%$ vs. $30.5 \%, P=0.01)$, mainly driven by markedly fewer incidences of nonfatal $\mathrm{MI}$ in the revascularization group than in the medical therapy group (7.4\% vs. $14.6 \%)$.

Figure 1 summarizes the relative treatment effect between intensive medical treatment alone and prompt initial coronary revascularization among total population, PCI-eligible patients, and CABG-eligible patients. However, BARI 2D was not designed to address whether PCI may produce outcome results similar to those of CABG in patients with extensive CAD. These comparisons have been recently addressed via important randomized clinical trials.

\section{Optimal Treatment Selection: CABG Versus PCI}

Two decades ago, a substudy of the BARI Trial $(n=353)$ showed a significant survival advantage of CABG over PCI with only balloon angioplasty at 5-year follow-up (5.8\% vs. $20.6 \%, P=0.0003)$ [15]. The diabetic subgroup analysis $(n=208)$ of the Arterial Revascularization Therapies Study (ARTS) Trial comparing BMS and CABG for multivessel CAD showed that PCI was significantly associated with a higher rate of repeat revascularization, but hard clinical endpoints were not different among the two revascularization strategies at 5-year follow-up [16]. A pooled analysis of individual patient data from 10 randomized trials suggested that among patients with diabetes, mortality was lower in the surgical group $(n=615)$ than in the PCI group $(n=618)$ $(23 \%$ vs. $29 \%$, hazard ratio $[\mathrm{HR}]=0.70$, 0.56-0.87) [17]. In contrast, registry data showed that patients with diabetes and multivessel disease had non-significant adjusted outcomes (death: $\mathrm{HR}=0.97, P=0.75$, death or MI: $\mathrm{HR}=0.84, P=0.07$ ) following PCI with DES $(n=3,256)$ compared with CABG $(n=2,844)$ [18].

Table 1 summarizes current evidence of clinical trials comparing DES and CABG for diabetic patients with multivessel CAD. In subgroup analysis of the Synergy Between Percutaneous Coronary Intervention with Taxus and Cardiac Surgery (SYNTAX) Trial, 452 patients had medically treated diabetes, 221 treated with CABG and 231 treated with PCI with paclitaxel-eluting stents (PES) [19]. At 1 year, the composite safety endpoint (death, stroke, or MI) was comparable between CABG and PCI for patients with diabetes $(10.3 \%$ vs. $10.1 \%)$ and without diabetes (6.8\% vs. $6.8 \%)$. But, MACE (death, MI, stroke, or repeat revascularization) difference between two treatment options (CABG vs. PCI) was significantly pronounced in patients with diabetes $(14.2 \%$ vs. $26.0 \%, P=0.003)$ than in patients without diabetes $(11.8 \%$ vs. $15.1 \%$, 

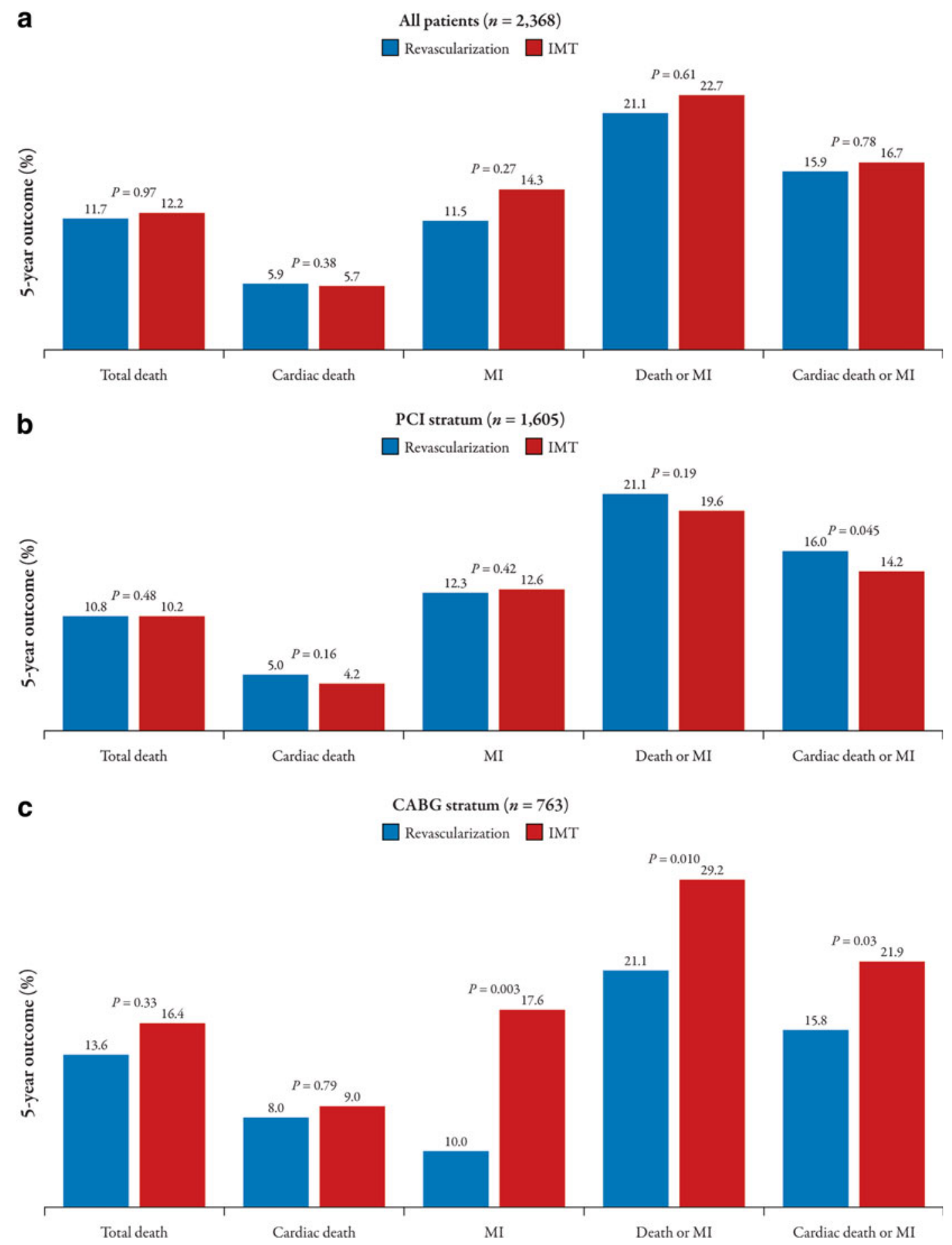

Fig. 1 5-year outcomes for death, cardiac death, MI, and the composite endpoints of death or MI, or of cardiac death or MI according to initial treatment strategy, and to percutaneous coronary intervention and coronary artery bypass grafting strata. Data are derived from The Bypass
Angioplasty Revascularization Investigation 2 Diabetes (BARI 2D) Trial. The Kaplan-Meier method was used to assess 5 -year event rates. $C A B G$ coronary artery bypass grafting, $I M T$ intensive medical therapy, $M I$ myocardial infarction, $P C I$ percutaneous coronary intervention 


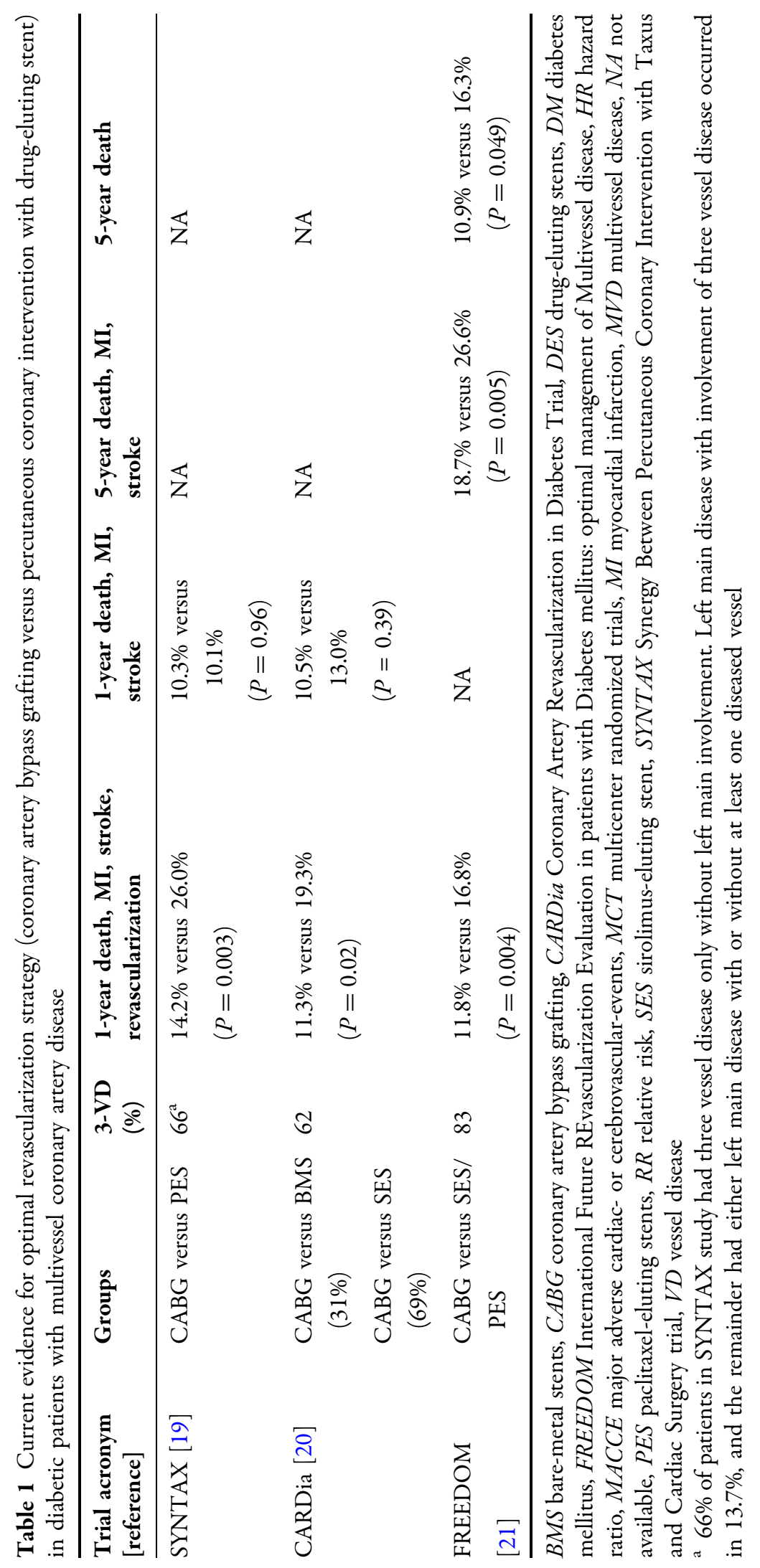


$P=0.08)$, which was mainly driven by higher repeat revascularization. The Coronary Artery Revascularization in Diabetes (CARDia) Trial was a diabetes-specific trial; 254 patients were treated with CABG and 256 patients with PCI. Primary endpoint (death, MI, or stroke) at 1 year was similar between the two groups. But, MACE including revascularization was significantly higher in the PCI group [20]. However, previous SYNTAX subgroup analysis and CARDia Trial were just hypothesis-generating or severely underpowered and therefore the evidence to guide the choice between CABG and PCI for patients with diabetes was very limited before the results from the International Future REvascularization Evaluation in patients with diabetes mellitus: optimal management of Multivessel disease (FREEDOM) Trial [21].

The FREEDOM Trial enrolled 1,900 patients with diabetes with multivessel CAD who were randomly assigned to either CABG or PCI using first-generation DES and the primary outcome measure was hard clinical endpoint (composite of death from any cause, nonfatal MI, or nonfatal stroke). At 5 years, the primary composite outcome occurred significantly more often in the PCI group than in the CABG group ( $26.6 \%$ vs. $18.7 \%, P=0.005)$. The benefit of CABG was driven by differences in rates of both MI (6.0\% vs. $13.9 \%, P<0.001)$ and death from any cause $(10.9 \%$ vs. $16.3 \%$, $P=0.049)$. However, stroke was more frequent in the CABG group (5.2\% vs. $2.4 \%, P=0.03)$. As expected, PCI was associated with significantly higher rates of repeat revascularization $(12.6 \%$ vs. $4.8 \%$; $\mathrm{HR}=2.74,95 \%$ CI 1.91-3.89). These findings were consistent among various highrisk subgroups (high SYNTAX score, low ejection fraction, and impaired renal function).

In clinical practice, the decision on coronary revascularization strategy in patients with diabetes should be based on the extent of
CAD, ischemic burden, ventricular function, clinical comorbidities, and patient's agreement. In those with multivessel disease, who can tolerate CABG surgery and have lesions that carry high risk for PCI, surgical revascularization would be the preferred approach. For patients with diabetes with single-vessel disease or less complex multivessel CAD, PCI with DES would be a reasonable alternative of standard CABG. Currently, based on compelling evidence of the FREEDOM Trial, the threshold for selection of CABG over PCI would be much lower in patients with diabetes than in those without. However, since first-generation DES were predominantly used in the FREEDOM trial, whether outcomes may be improved with the use of new-generation DES is a matter of debate, and therefore future trials comparing second- or newer-generation DES and CABG should be performed to reassess the relative treatment effect in patients with diabetes.

\section{PCI in Diabetes}

\section{BMS Versus First-Generation DES}

Patients with diabetes have a higher burden of atherosclerosis, smaller coronary arteries, larger extents of diseased segments, and a higher risk of repeat revascularization after PCI than do patients without diabetes. Considering the marked improvement of efficacy regarding restenosis and repeat revascularization, the use of DES is preferable to the use of BMS for diabetic patients with complex angiographic features and higher tendency of restenosis. The selection of a specific type of DES in patients with diabetes is still controversial.

The relative efficacy and safety of firstgeneration DES (SES and PES) compared to BMS in patients with diabetes have been evaluated in many of the early stent trials. A 
collaborative network meta-analysis of 35 trials comparing BMS, SES, and PES, which included 3,852 patients with diabetes, showed that that DES were as safe as BMS in patients with diabetes when dual antiplatelet therapy was prescribed for 6 months or more. In addition, the reduction in the risk of repeat revascularization was significantly lower in SES and PES compared to BMS and the risk with the use of DES in patients with diabetes was similar to the risk reduction in patients without diabetes [22].

By contrast, in a real-world registry including 5,051 adult patients with DM undergoing PCI (3,341 treated with DES and 1,710 treated with BMS), there was a significant reduction in riskadjusted mortality (17.5\% vs. $20.7 \% ; P=0.02)$, MI $(13.8 \%$ vs. $16.9 \% ; P=0.02)$, and repeat revascularization $(18.4 \%$ vs. $23.7 \% ; P<0.001)$ associated with DES versus BMS at 3-year longterm follow-up [23].

\section{First-Generation DES: SES Versus PES}

The relative efficacy and safety of SES and PES in patients with diabetes has been evaluated in several clinical studies. The direct and indirect network analysis showed that there was no difference found in death or MI between SES and PES in patients with diabetes, but the rate of repeat revascularization was lower after use of SES compared with PES [22]. In contrast, a subsequent meta-analysis of over 12,000 patients with diabetes including several randomized controlled trials (RCT) and observational studies showed that the risks of MACE and repeat revascularization were similar between PES and SES [24]. In a subset of 13 RCTs, the rates for MACE (PES: $15.4 \%$ vs. SES: 12.9\%) and TLR (PES: $8.6 \%$ vs. SES: $7.6 \%$ ) were similar between two stents, and in subset of 16 registries, the rates for MACE (PES: 10.1\% vs. SES: $11.9 \%)$ and target-vessel revascularization
(TVR) (PES: $5.8 \%$ vs. SES: $7.2 \%$ ) were also similar. Recently, long-term results of a metaanalysis including six RCTs comparing SES and PES in diabetic population showed that the use of SES was significantly associated with 35\% reduction of TLR compared to PES, but there were no differences of safety outcomes in terms of death or MI, and stent thrombosis at a median follow-up of 4 years [25].

\section{Second-Generation DES}

Since early-generation DES had been widely used and long-term safety issues had been raised, new platforms for DES that are aimed at improving safety and efficacy have been developed. First-generation DES released sirolimus or paclitaxel and had stainless-steel platforms, whereas new-generation DES release zotarolimus or everolimus and feature cobaltchrome or platinum-chrome platforms with thinner strut thickness and more biocompatible, durable polymer coatings. These new-generation stents have almost replaced first-generation DES in routine clinical practice, and SES is no longer manufactured.

In comparison of Endeavor ${ }^{\circledR}$ zotarolimuseluting stents (ZES) (Medtronic, Inc., Santa Rosa, CA, USA) with a first-generation DES, a substudy of the ENDEAVOR IV Clinical Trial: A Trial of a Coronary Stent System in Coronary Artery Lesions (known as ENDEAVOR IV) (477 diabetic population) showed that 1-year clinical outcomes were similar (target-vessel failure (TVF): $8.6 \%$ vs. 9.4\%) after Endeavor ZES and PES [26]. By contrast, a diabetic subgroup of the Scandinavian Organization for Randomized Trials With Clinical Outcome III (SORT-OUT III) Trial showed that implantation of Endeavor ZES compared to an SES is associated with a considerably increased risk of the MACE (18.3\% vs. $4.8 \%$ ) and repeat revascularization at 18-month follow-up [27]. A subgroup analysis 
of the Comparison of the Efficacy and Safety of Zotarolimus-Eluting Stent versus SirolimusEluting Stent and PacliTaxel-Eluting Stent for Coronary Lesions (ZEST) Trial ( $n=760$ diabetic population) comparing Endeavor ZES versus SES and PES showed that primary endpoint (death, MI, TVR) at 12 months after use of Endeavor ZES were similar to the PES (13.8\% vs. $15.3 \%)$, but was significantly higher compared to SES (13.8\% vs. $7.7 \%$ ) [28]. Recently, in the PatientRelated Outcomes with Endeavor versus Cypher Stenting Trial (PROTECT), involving 8,791 patients comparing Endeavor ZES with SES, there was no difference in the primary endpoint of definite or probable stent thrombosis at 3 years [29]. Similarly, the risk of death or MI was similar with the two types of DES. In a prespecified diabetic subgroup analysis $(n=2,410)$, similar findings were observed. However, the risk of repeat revascularization was significantly higher with Endeavor ZES.

In several randomized trials, everolimuseluting stent (EES) improved clinical outcomes as compared with PES, reducing the risks of repeat revascularization, MI, and stent thrombosis; the Clinical Evaluation of the XIENCE V Everolimus Eluting Coronary Stent System (SPIRIT) II [30] $\quad(n=300, \quad 23.1 \%$ diabetes), SPIRIT III [31] $(n=1,002,29.0 \%$ diabetes), SPIRIT IV [32] $(n=3,687,32.4 \%$ diabetes) and the Comparison of the everolimus-eluting XIENCE-V stent with the paclitaxel-eluting TAXUS LIBERTÉ stent in allcomers: a randomized open label trial (COMPARE) [33] ( $n=1,799,18.1 \%$ diabetes). Merged analyses of these clinical trials compared the relative treatment effect of EES and PES according to the diabetic status [34]. Compared to the remarkable benefit of EES over PES in patients without diabetes, no significant differences of clinical outcomes were seen between the two stent types in patients with diabetes. A significant interaction was found between the presence of diabetes and stent type for the 2-year occurrence of MI $(P=0.01)$, stent thrombosis $(P=0.0006)$, and ischemia-driven TLR $(P=0.02)$. Further studies might be required to explain the underlying mechanism of diabetic-related interaction on clinical outcomes according to different DES types. Randomized comparisons showed similar outcomes for EES and SES with respect to rates of death, MI, and repeat revascularization, and these results were also maintained in diabetic population $[35,36]$. The randomized comparison of everolimus-eluting stent versus sirolimus-eluting stent implantation for de novo CAD in patients with diabetes mellitus (ESSENCE-DIABETES) Trial [37], which was specifically designed to evaluate EES versus SES in 300 patients with diabetes, showed noninferiority of EES to SES in reducing insegment late loss and angiographic restenosis at 8 months. However, in 1-year clinical outcomes of ischemia-driven TLR, death and MI showed similar outcomes. In the Interventional Cardiology Research In-Cooperation SocietyDrug-Eluting Stents (IRIS-DES) Registry [38], 6,166 consecutive patients who received either EES or SES were enrolled and $34.8 \%(2,145)$ were diabetics. This study showed that 2-year MACE in the overall group as well as the diabetic group was similar. In contrast to a significant interaction between diabetic status and EES versus PES, no such interaction was found among EES versus SES.

A newer-version of ZES, the Resolute ${ }^{\mathrm{TM}}$ ZES (Medtronic, Inc. Santa Rosa, CA, USA) was developed using a dual polymer technology that extends the release of zotarolimus and drug exposure to the vessel to 4 months [44]. Among several second-generation DES, the Resolute ZES has been approved as specific indication for 
patients with diabetes by the United States Food and Drug Administration, based on a prespecified analysis from the Resolute US clinical trial in which the outcome for death, MI, and TLR was similar to patients without diabetes [39]. The Resolute ZES was compared with the EES in two large-scale trials; A Randomized Comparison of a ZotarolimusEluting Stent With an Everolimus-Eluting Stent for Percutaneous Coronary Intervention (RESOLUTE All Comers) Trial [40], and a randomized controlled trial in secondgeneration zotarolimus-eluting Resolute stents versus everolimus-eluting Xience $\mathrm{V}$ stents in real-world patients: the TWENTE Trial [41], which showed similar risks of cardiac death, MI, repeat revascularization, and stent thrombosis throughout a 2-year period. In a diabetic subgroup of each trial, HRs for primary endpoint nonsignificantly favored EES rather than Resolute ZES (RESOLUTE All Comer; 1.45
[0.82-2.59], $P=0.25$ and TWENTE; 1.81 $[0.91-3.60], P=0.08)$. However, due to the nature of subgroup analysis, these findings are considered to be primarily hypothesisgenerating and more specific clinical trials comparing Resolute ZES and EES targeting the diabetic population are warranted.

A recent network meta-analysis comparing outcomes with various DES (SES, PES, EES, and ZES) or BMS in 22,844 patients with diabetes showed that currently used DESs are more efficient at reducing the risk of TLR without compromising safety outcomes, as compared with BMS [42]. There are considerable differences in the relative efficacy and safety profiles of various DESs and EES seems to be the most efficient and the safest of the currently available DES in patients with diabetes. Figure 2 illustrates the probability of several DES and BMS producing the best outcomes in terms of efficacy and safety endpoints for patients with

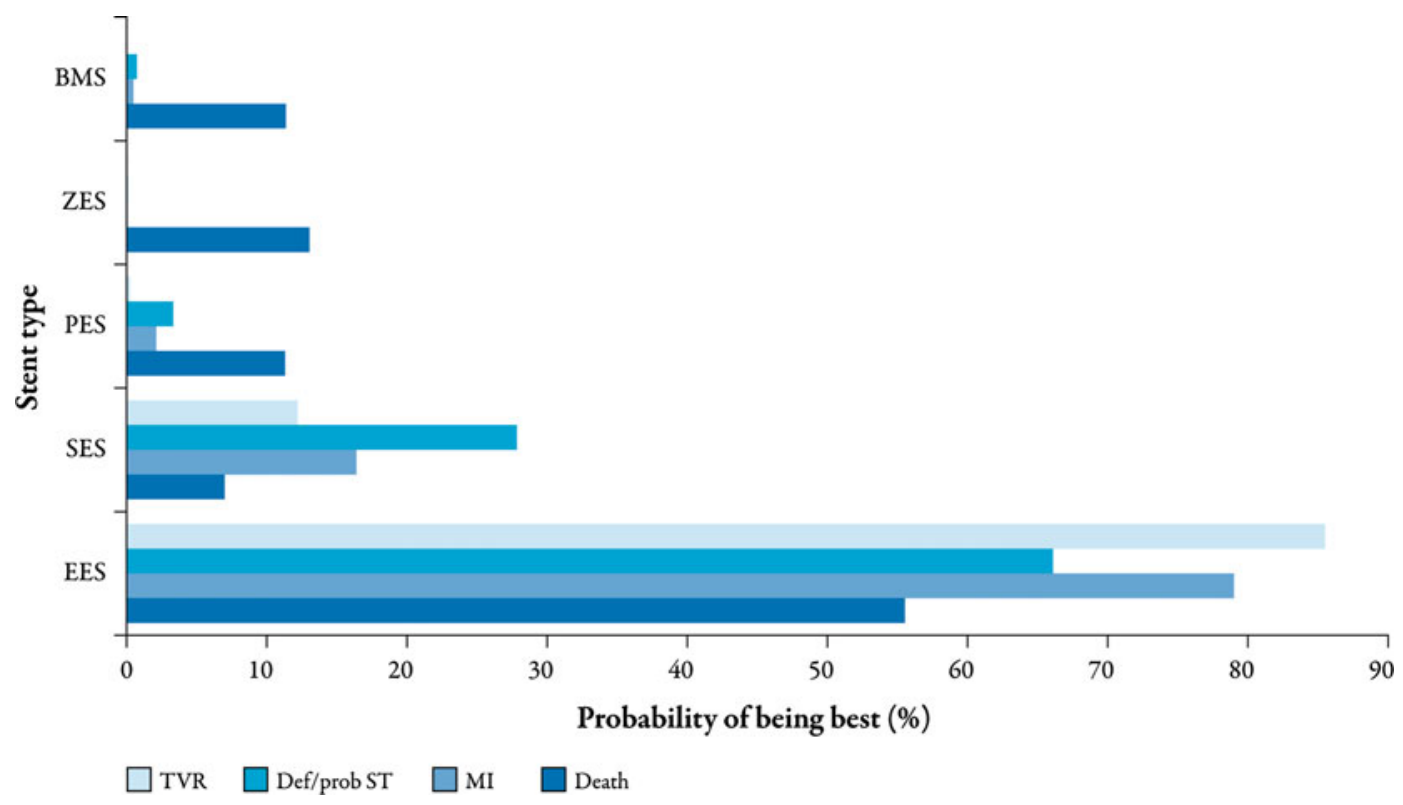

Fig. 2 Several stents comparisons (drug-eluting stents and bare-metal stents) for patients with diabetes. BMS baremetal stents, Def/prob $S T$ definite or probable stent thrombosis, $D E S$ drug-eluting stent, EES everolimus-

eluting stents, $M I$ myocardial infarction, PES paclitaxeleluting stents, SES sirolimus-eluting stents, TVR targetvessel revascularization, $Z E S$ zotarolimus-eluting stents. Comparing data for Resolute ZES is limited 
diabetes. However, more data comparing EES, Resolute EES, and biodegradable polymer DES for diabetic patients are currently required, and no definitive conclusion regarding the comparative propensity for safety and efficacy outcomes with specific DES for diabetic population can be derived from current available data.

To overcome the proinflammatory stimulus of durable polymers, biodegradable polymerbased DESs have been developed. Theoretically, this platform would be more useful for patients with diabetes with complicated anatomic features predisposing to stent thrombosis and long-term safety issues. The primary results of the Limus Eluted from A Durable versus ERodable Stent coating (LEADERS) Trial showed similar safety and effectiveness of biodegradable polymer biolimus-eluting stent (BES) compared with durable polymer SES at 9 months [43]. The relative treatment effects were consistent in patients with (rate ratio 1.03, 95\% CI 0.61-1.75) and without (rate ratio 0.78, 95\% CI 0.54-1.14) diabetes. These findings were maintained up to 4 years [44]. A fully bioabsorbable DES temporarily scaffolds the vessel wall and then disappears once the acute recoil and constrictive remodeling processes have subsided [45]. If sufficient clinical data are obtained in future clinical trials, this system might be very useful especially for diabetic patients with a higher chance of being treated with subsequent CABG. Currently, there are still very limited data regarding the general performance and outcomes of bioabsorbable DES for patients with diabetes.

\section{Adjunctive Drug Therapies in Diabetic Patients Receiving PCI}

The effect of glycemic control on PCI outcomes among diabetic patients has been investigated in previous study [46]. This study suggested that the rate of clinical restenosis after PCI in patients with diabetes might be significantly lower if optimal glycemic control was achieved; patients with diabetes with a preprocedural glycosylated hemoglobin (HbA1c) of $\leq 7 \%$ had a similar rate of 1-year TVR compared patients without diabetes (15\% vs. 18\%), whereas patients with diabetes with an $\mathrm{HbA1c}>7 \%$ had a significantly higher rate of TVR (34\%). Experimentally, thiazolidinediones have been suggested to suppress intimal proliferation after vascular injury. The potential efficacy of this approach in diabetic patients undergoing PCI has been evaluated in two small randomized trials using pioglitazone [47] or rosiglitazone [48] and lower rates of angiographic restenosis were found in the experimental group. However, due to limited sample size and lack of clinical benefit, larger studies are needed for definite conclusions.

Dual antiplatelet therapy with aspirin and a P2Y12 inhibitor reduces the risk of ischemic events after stent placement. However, as compared with patients without diabetes, the efficacy of antiplatelet agents is significantly reduced in patients with diabetes, due to platelet hyper-reactivity and relatively poor response to antiplatelet therapy $[49,50]$. Until now, several studies testing novel antiplatelet agents suggested that platelet inhibition could be further enhanced among patients with diabetes receiving PCI. Results of diabetic subgroup analyses from major pharmacologic clinical trials comparing prasugrel [51, 52], ticagrelor [53], high-dose clopidogrel [54], and vorapaxar [55], as compared to standard clopidogrel therapy are shown in Table 2. Overall, although it was not always statistically significant, treatment effect favored new antiplatelet agents or regimens over standard regimen. 


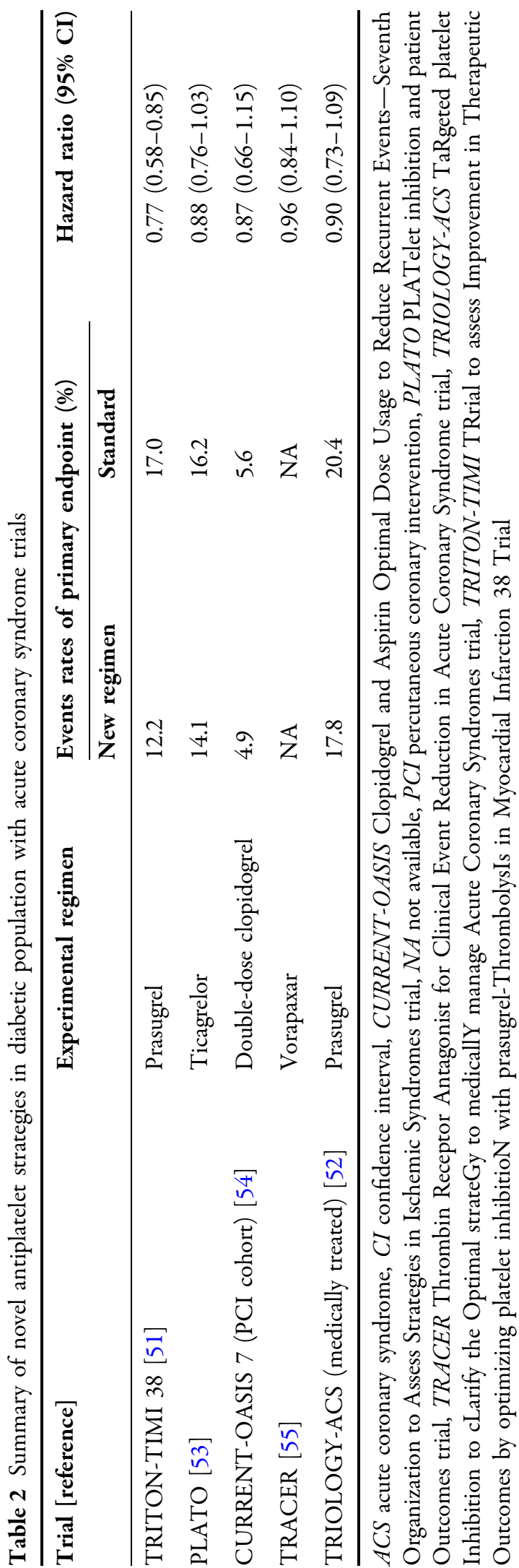

In subgroup analyses the relative efficacy and safety of glycoprotein (GP) IIb/IIIa inhibitors in patients with diabetes appear to be similar to those without diabetes $[56,57]$. In contrast, two meta-analyses using pooled trial data suggested that patients with diabetes may benefit more than those without diabetes with a significant mortality reduction at 30 days and 1 year $[58$, 59]. However, the diabetic-specific Intracoronary Stenting and Antithrombotic Regimen: Is Abciximab a Superior Way to Eliminate Elevated Thrombotic Risk in Diabetics (ISAR-SWEET) Trial [60], in which 701 diabetic patients were randomized to receive abciximab versus placebo add-on conventional heparin and $600 \mathrm{mg}$ clopidogrel loading, showed that the primary endpoint of death or MI at 1-year follow-up did not differ between the two groups ( $8.3 \%$ vs. $8.6 \%)$, and there was no difference in mortality ( $4.8 \%$ vs. $5.1 \%)$.

\section{CONCLUSIONS}

For patients with diabetes with significant CAD, the decision when and how to proceed to coronary revascularization should be based on multiple parameters including patient characteristics, comorbidities, clinical presentation, coronary anatomy and lesion complexity, ischemic burden, left ventricular function, and patients preference. Since decision-making in patients with diabetes is frequently complicated, such a decision is reasonable to be made after discussion in a multidisciplinary "heart team." Based on compelling evidence of the FREEDOM Trial, the threshold for selecting CABG over PCI would be lower in patients with diabetes than in patients without.

With marked advances of stent device technology and adjunctive pharmacology, PCI 
with DES has become one of the efficient revascularization strategies for patients with diabetes. Compared with BMS, the currently used DES are more efficacious at reducing the risk of restenosis and repeat revascularization without compromising safety outcomes, including mortality and late stent thrombosis in patients with diabetes. Among several DES, network meta-analysis indirectly suggest that EES seems to be the most efficacious and safest for use in patients with diabetes. However, since direct comparison trials among EES, Resolute, biodegradable polymer DES, and newer versions of DES for patients with diabetes are limited, the selection of a specific type of DES in patients with diabetes is still controversial.

\section{ACKNOWLEDGMENTS}

Dr. Duk-Woo Park is the guarantor for this article, and takes responsibility for the integrity of the work as a whole. No funding or sponsorship was received for this study or publication of this article.

Conflict of interest. Dr. Duk-Woo Park and Dr. Ralf Harskamp declare no conflict of interest.

Open Access. This article is distributed under the terms of the Creative Commons Attribution Noncommercial License which permits any noncommercial use, distribution, and reproduction in any medium, provided the original author(s) and the source are credited.

\section{REFERENCES}

1. Grundy SM, Benjamin IJ, Burke GL, Chait A, Eckel $\mathrm{RH}$, Howard BV, et al. Diabetes and cardiovascular disease: a statement for healthcare professionals from the American Heart Association. Circulation. 1999;100:1134-46.

2. Hammoud T, Tanguay JF, Bourassa MG. Management of coronary artery disease: therapeutic options in patients with diabetes. J Am Coll Cardiol. 2000;3:355-65.

3. Roffi M, Angiolillo DJ, Kappetein AP. Current concepts on coronary revascularization in diabetic patients. Eur Heart J. 2011;32:2748-57.

4. Stefanini GG, Holmes DR, Jr. Drug-eluting coronary-artery stents. N Engl J Med. 2013; 368:254-65.

5. Carson JL, Scholz PM, Chen AY, Peterson ED, Gold J, Schneider SH. Diabetes mellitus increases shortterm mortality and morbidity in patients undergoing coronary artery bypass graft surgery. J Am Coll Cardiol. 2002;40:418-23.

6. Matsa M, Paz Y, Gurevitch J, Shapira I, Kramer A, Pevny D, et al. Bilateral skeletonized internal thoracic artery grafts in patients with diabetes mellitus. J Thorac Cardiovasc Surg. 2001; 121:668-74.

7. Desai ND, Naylor CD, Kiss A, Cohen EA, FederElituv R, Miwa S, et al. Impact of patient and targetvessel characteristics on arterial and venous bypass graft patency: insight from a randomized trial. Circulation. 2007;115:684-91.

8. West NE, Ruygrok PN, Disco CM, Webster MW, Lindeboom WK, O'Neill WW, et al. Clinical and angiographic predictors of restenosis after stent deployment in diabetic patients. Circulation. 2004;109:867-73.

9. Mehran R, Dangas GD, Kobayashi Y, Lansky AJ, Mintz GS, Aymong ED, et al. Short- and long-term results after multivessel stenting in diabetic patients. J Am Coll Cardiol. 2004;43:1348-54.

10. Schofer J, Schluter M, Rau T, Hammer F, Haag N, Mathey DG. Influence of treatment modality on angiographic outcome after coronary stenting in diabetic patients: a controlled study. J Am Coll Cardiol. 2000;35:1554-9.

11. Tada T, Kimura T, Morimoto T, Ono K, Furukawa Y, Nakagawa $Y$, et al. Comparison of three-year clinical outcomes after sirolimus-eluting stent implantation among insulin-treated diabetic, noninsulin-treated diabetic, and non-diabetic patients from j-Cypher registry. Am J Cardiol. 2011; 107:1155-62.

12. Elezi S, Kastrati A, Pache J, Wehinger A, Hadamitzky M, Dirschinger J, et al. Diabetes mellitus and the clinical and angiographic outcome after coronary 
stent placement. J Am Coll Cardiol. 1998;32:1866-73.

13. Iijima R, Ndrepepa G, Mehilli J, Markwardt C, Bruskina $\mathrm{O}$, Pache $\mathrm{J}$, et al. Impact of diabetes mellitus on long-term outcomes in the drugeluting stent era. Am Heart J. 2007;154:688-93.

14. Frye RL, August P, Brooks MM, Hardison RM, Kelsey $\mathrm{SF}$, MacGregor JM, et al. A randomized trial of therapies for type 2 diabetes and coronary artery disease. N Engl J Med. 2009;360:2503-15.

15. The BARI Investigators. Influence of diabetes on 5-year mortality and morbidity in a randomized trial comparing CABG and PTCA in patients with multivessel disease: the Bypass Angioplasty Revascularization Investigation (BARI). Circulation. 1997;96:1761-9.

16. Serruys PW, Ong AT, van Herwerden LA, Sousa JE, Jatene A, Bonnier JJ, et al. Five-year outcomes after coronary stenting versus bypass surgery for the treatment of multivessel disease: the final analysis of the Arterial Revascularization Therapies Study (ARTS) randomized trial. J Am Coll Cardiol. 2005;46:575-81.

17. Hlatky MA, Boothroyd DB, Bravata DM, Boersma E, Booth J, Brooks MM, et al. Coronary artery bypass surgery compared with percutaneous coronary interventions for multivessel disease: a collaborative analysis of individual patient data from ten randomised trials. Lancet. 2009;373:1190-7.

18. Hannan EL, Wu C, Walford G, Culliford AT, Gold JP, Smith CR, et al. Drug-eluting stents vs. coronaryartery bypass grafting in multivessel coronary disease. N Engl J Med. 2008;358:331-41.

19. Banning AP, Westaby S, Morice MC, Kappetein AP, Mohr FW, Berti S, et al. Diabetic and nondiabetic patients with left main and/or 3-vessel coronary artery disease: comparison of outcomes with cardiac surgery and paclitaxel-eluting stents. J Am Coll Cardiol. 2010;55:1067-75.

20. Kapur A, Hall RJ, Malik IS, Qureshi AC, Butts J, de Belder $M$, et al. Randomized comparison of percutaneous coronary intervention with coronary artery bypass grafting in diabetic patients. 1-year results of the CARDia (Coronary Artery Revascularization in Diabetes) trial. J Am Coll Cardiol. 2010;55:432-40.

21. Farkouh ME, Domanski M, Sleeper LA, Siami FS, Dangas G, Mack M, et al. Strategies for multivessel revascularization in patients with diabetes. N Engl J Med. 2012;367:2375-84.

22. Stettler C, Allemann S, Wandel S, Kastrati A, Morice $\mathrm{MC}$, Schomig A, et al. Drug eluting and bare metal stents in people with and without diabetes: collaborative network meta-analysis. BMJ. 2008;337:a1331.

23. Garg P, Normand SL, Silbaugh TS, Wolf RE, Zelevinsky K, Lovett A, et al. Drug-eluting or baremetal stenting in patients with diabetes mellitus: results from the Massachusetts Data Analysis Center Registry. Circulation. 2008;118:2277-85.

24. Mahmud E, Bromberg-Marin G, Palakodeti V, Ang L, Creanga D, Demaria AN. Clinical efficacy of drugeluting stents in diabetic patients: a meta-analysis. J Am Coll Cardiol. 2008;51:2385-95.

25. Kufner S, de Waha A, Tomai F, Park SW, Lee SW, Lim DS, et al. A meta-analysis of specifically designed randomized trials of sirolimus-eluting versus paclitaxel-eluting stents in diabetic patients with coronary artery disease. Am Heart J. 2011;162:740-7.

26. Kirtane AJ, Patel R, O'Shaughnessy C, Overlie P, McLaurin B, Solomon S, et al. Clinical and angiographic outcomes in diabetics from the ENDEAVOR IV trial: randomized comparison of zotarolimus- and paclitaxel-eluting stents in patients with coronary artery disease. JACC Cardiovasc Interv. 2009;2:967-76.

27. Maeng M, Jensen LO, Tilsted HH, Kaltoft A, Kelbaek $\mathrm{H}$, Abildgaard $\mathrm{U}$, et al. Outcome of sirolimuseluting versus zotarolimus-eluting coronary stent implantation in patients with and without diabetes mellitus (a SORT OUT III Substudy). Am J Cardiol. 2011;108:1232-7.

28. Jang SJ, Park DW, Kim WJ, Kim YH, Yun SC, Kang $\mathrm{SJ}$, et al. Differential long-term outcomes of zotarolimus-eluting stents compared with sirolimus-eluting and paclitaxel-eluting stents in diabetic and non-diabetic patients: 2-year subgroup analysis of the ZEST randomized trial. Catheter Cardiovasc Interv. 2012. doi:10.1002/ccd.24603 [Epub ahead of print].

29. Camenzind E, Wijns W, Mauri L, Kurowski V, Parikh K, Gao R, et al. Stent thrombosis and major clinical events at 3 years after zotarolimus-eluting or sirolimus-eluting coronary stent implantation: a randomised, multicentre, open-label, controlled trial. Lancet. 2012;380:1396-405.

30. Claessen BE, Beijk MA, Legrand V, Ruzyllo W, Manari A, Varenne $\mathrm{O}$, et al. Two-year clinical, angiographic, and intravascular ultrasound followup of the XIENCE V everolimus-eluting stent in the treatment of patients with de novo native coronary artery lesions: the SPIRIT II trial. Circ Cardiovasc Interv. 2009;2:339-47.

31. Stone GW, Midei M, Newman W, Sanz M, Hermiller JB, Williams J, et al. Comparison of an everolimus- 
eluting stent and a paclitaxel-eluting stent in patients with coronary artery disease: a randomized trial. JAMA. 2008;299:1903-13.

32. Stone GW, Rizvi A, Newman W, Mastali K, Wang JC, Caputo R, et al. Everolimus-eluting versus paclitaxel-eluting stents in coronary artery disease. N Engl J Med. 2010;362:1663-74.

33. Kedhi E, Joesoef KS, McFadden E, Wassing J, van Mieghem C, Goedhart D, et al. Second-generation everolimus-eluting and paclitaxel-eluting stents in real-life practice (COMPARE): a randomised trial. Lancet. 2010;375:201-9

34. Stone GW, Kedhi E, Kereiakes DJ, Parise H, Fahy M, Serruys PW, et al. Differential clinical responses to everolimus-eluting and Paclitaxel-eluting coronary stents in patients with and without diabetes mellitus. Circulation. 2011;124:893-900.

35. Kaiser C, Galatius S, Erne P, Eberli F, Alber H, Rickli H, et al. Drug-eluting versus bare-metal stents in large coronary arteries. N Engl J Med. 2010;363:2310-9.

36. Kimura $T$, Morimoto $T$, Natsuaki $M$, Shiomi $H$, Igarashi $\mathrm{K}$, Kadota $\mathrm{K}$, et al. Comparison of everolimus-eluting and sirolimus-eluting coronary stents: 1-year outcomes from the Randomized Evaluation of Sirolimus-eluting Versus Everolimuseluting stent Trial (RESET). Circulation. 2012;126:1225-36.

37. Kim WJ, Lee SW, Park SW, Kim YH, Yun SC, Lee JY, et al. Randomized comparison of everolimuseluting stent versus sirolimus-eluting stent implantation for de novo coronary artery disease in patients with diabetes mellitus (ESSENCEDIABETES): results from the ESSENCE-DIABETES trial. Circulation. 2011;124:886-92.

38. Park DW, Kim YH, Song HG, Ahn JM, Kim WJ, Lee $\mathrm{JY}$, et al. Outcomes after unrestricted use of everolimus-eluting and sirolimus-eluting stents in routine clinical practice: a multicenter, prospective cohort study. Circ Cardiovasc Interv. 2012;5:365-71.

39. Yeung AC, Leon MB, Jain A, Tolleson TR, Spriggs DJ, Mc Laurin BT, et al. Clinical evaluation of the Resolute zotarolimus-eluting coronary stent system in the treatment of de novo lesions in native coronary arteries: the RESOLUTE US clinical trial. J Am Coll Cardiol. 2011;57:1778-83.

40. Serruys PW, Silber S, Garg S, van Geuns RJ, Richardt G, Buszman PE, et al. Comparison of zotarolimuseluting and everolimus-eluting coronary stents. N Engl J Med. 2010;363:136-46.

41. von Birgelen $\mathrm{C}$, Basalus MW, Tandjung $\mathrm{K}$, van Houwelingen KG, Stoel MG, Louwerenburg JH, et al. A randomized controlled trial in secondgeneration zotarolimus-eluting Resolute stents versus everolimus-eluting Xience $\mathrm{V}$ stents in realworld patients: the TWENTE trial. J Am Coll Cardiol. 2012;59:1350-61.

42. Bangalore S, Kumar S, Fusaro M, Amoroso N, Kirtane AJ, Byrne RA, et al. Outcomes with various drug eluting or bare metal stents in patients with diabetes mellitus: mixed treatment comparison analysis of 22,844 patient years of follow-up from randomised trials. BMJ. 2012;345:e5170.

43. Windecker S, Serruys PW, Wandel S, Buszman P, Trznadel S, Linke A, et al. Biolimus-eluting stent with biodegradable polymer versus sirolimuseluting stent with durable polymer for coronary revascularisation (LEADERS): a randomised noninferiority trial. Lancet. 2008;372:1163-73.

44. Stefanini GG, Kalesan B, Serruys PW, Heg D, Buszman P, Linke A, et al. Long-term clinical outcomes of biodegradable polymer biolimuseluting stents versus durable polymer sirolimuseluting stents in patients with coronary artery disease (LEADERS): 4 year follow-up of a randomised non-inferiority trial. Lancet. 2011;378:1940-8.

45. Ormiston JA, Serruys PW, Regar E, Dudek D, Thuesen L, Webster MW, et al. A bioabsorbable everolimus-eluting coronary stent system for patients with single de-novo coronary artery lesions (ABSORB): a prospective open-label trial. Lancet. 2008;371:899-907.

46. Corpus RA, George PB, House JA, Dixon SR, Ajluni $\mathrm{SC}$, Devlin WH, et al. Optimal glycemic control is associated with a lower rate of target vessel revascularization in treated type II diabetic patients undergoing elective percutaneous coronary intervention. J Am Coll Cardiol. 2004;43:8-14.

47. Nishio K, Sakurai M, Kusuyama T, Shigemitsu M, Fukui T, Kawamura K, et al. A randomized comparison of pioglitazone to inhibit restenosis after coronary stenting in patients with type 2 diabetes. Diabetes Care. 2006;29:101-6.

48. Choi D, Kim SK, Choi SH, Ko YG, Ahn CW, Jang Y, et al. Preventative effects of rosiglitazone on restenosis after coronary stent implantation in patients with type 2 diabetes. Diabetes Care. 2004;27:2654-60.

49. Angiolillo DJ, Fernandez-Ortiz A, Bernardo E, Ramirez C, Sabate M, Jimenez-Quevedo P, et al. Platelet function profiles in patients with type 2 diabetes and coronary artery disease on combined aspirin and clopidogrel treatment. Diabetes. 2005;54:2430-5. 
50. Angiolillo DJ, Bernardo E, Ramirez C, Costa MA, Sabate M, Jimenez-Quevedo P, et al. Insulin therapy is associated with platelet dysfunction in patients with type 2 diabetes mellitus on dual oral antiplatelet treatment. J Am Coll Cardiol. 2006;48:298-304.

51. Wiviott SD, Braunwald E, Angiolillo DJ, Meisel S, Dalby AJ, Verheugt FW, et al. Greater clinical benefit of more intensive oral antiplatelet therapy with prasugrel in patients with diabetes mellitus in the trial to assess improvement in therapeutic outcomes by optimizing platelet inhibition with prasugrel-Thrombolysis in Myocardial Infarction 38. Circulation. 2008;118:1626-36.

52. Roe MT, Ohman EM. Prasugrel versus clopidogrel for acute coronary syndromes. $N$ Engl J Med. 2013;368:188-9.

53. James S, Angiolillo DJ, Cornel JH, Erlinge D, Husted S, Kontny F, et al. Ticagrelor vs. clopidogrel in patients with acute coronary syndromes and diabetes: a substudy from the PLATelet inhibition and patient Outcomes (PLATO) trial. Eur Heart J. 2010;31:3006-16.

54. Mehta SR, Tanguay JF, Eikelboom JW, Jolly SS, Joyner $\mathrm{CD}$, Granger CB, et al. Double-dose versus standarddose clopidogrel and high-dose versus low-dose aspirin in individuals undergoing percutaneous coronary intervention for acute coronary syndromes (CURRENT-OASIS 7): a randomised factorial trial. Lancet. 2010;376:1233-43.

55. Tricoci P, Huang Z, Held C, Moliterno DJ, Armstrong PW, Van de Werf F, et al. Thrombin- receptor antagonist vorapaxar in acute coronary syndromes. N Engl J Med. 2012;366:20-33.

56. Marso SP, Lincoff AM, Ellis SG, Bhatt DL, Tanguay JF, Kleiman NS, et al. Optimizing the percutaneous interventional outcomes for patients with diabetes mellitus: results of the EPISTENT (Evaluation of platelet IIb/IIIa inhibitor for stenting trial) diabetic substudy. Circulation. 1999;100:2477-84.

57. Kastrati A, Mehilli J, Schuhlen H, Dirschinger J, Dotzer F, ten Berg JM, et al. A clinical trial of abciximab in elective percutaneous coronary intervention after pretreatment with clopidogrel. N Engl J Med. 2004;350:232-8.

58. Bhatt DL, Marso SP, Lincoff AM, Wolski KE, Ellis SG, Topol EJ. Abciximab reduces mortality in diabetics following percutaneous coronary intervention. J Am Coll Cardiol. 2000;35:922-8.

59. Roffi M, Chew DP, Mukherjee D, Bhatt DL, White JA, Heeschen C, et al. Platelet glycoprotein IIb/IIIa inhibitors reduce mortality in diabetic patients with non-ST-segment-elevation acute coronary syndromes. Circulation. 2001;104:2767-71.

60. Mehilli J, Kastrati A, Schuhlen H, Dibra A, Dotzer F, von Beckerath $\mathrm{N}$, et al. Randomized clinical trial of abciximab in diabetic patients undergoing elective percutaneous coronary interventions after treatment with a high loading dose of clopidogrel. Circulation. 2004;110:3627-35. 